Case Report

\title{
Salivary duct carcinoma of sublingual salivary gland: a rare case report
}

\begin{abstract}
The salivary duct carcinoma represents a rare variant of the group of adenocarcinomas originated from the salivary glands, especially extremely rare from sublingual salivary gland origin. We report a case of a salivary duct carcinoma of the sublingual salivary gland in a 61-year-old man. Incisional biopsy was done and the diagnosis of salivary duct carcinoma of sublingual salivary gland was given by histopathological report.
\end{abstract}

Keywords: salivary duct carcinoma, sublingual salivary gland, comedocarcinoma of the breast

\author{
Volume 6 Issue 3 - 2017 \\ Sheraz BS,' Srilatha T,' Zohair Hussain Khan \\ M,' Abdul Habeeb Bin Mohsin ${ }^{2}$ \\ 'Department of Oral \& Maxillofacial Surgery, MNR Dental \\ College \& Hospital, India \\ ${ }^{2}$ Department of Prosthodontics, Sri Sai College of Dental \\ Surgery, India
}

\begin{abstract}
Correspondence: Sheraz BS, Department of Oral \& Maxillofacial Surgery, MNR Dental College \& Hospital, Sangareddy, Telangana, India, Email doc.habeeb@gmail.com
\end{abstract}

Received: January 07, 2017 | Published: February 08, 2017

\section{Introduction}

Salivary duct carcinoma is a rare tumor accounting for $1 \%$ to $3 \%$ of all malignant salivary gland tumors. ${ }^{1,2}$ Initially, a group of malignant salivary gland tumors characterized by ductal formations and central necrosis was first described by Kleinsasser et al. ${ }^{3}$ only few cases have been repoted in literature till date.

\section{Case presentation}

A 61-year-old Indian male reported to the Department of Oral \& Maxillofacial Surgery, with the chief complaint of a swelling in the floor of the mouth since 2 weeks. He had noticed a small, painless swelling on the floor of the mouth, which had grown to the present size. He had difficulty in mastication, swallowing and talking. No relevant medical history. Intraoral inspection revealed a solitary, well-defined, round swelling, on the floor of the mouth (approximately $1 \times 2 \mathrm{~cm}$ in size), obliterating the lingual vestibule. The surface of the swelling was ulcerated and bleeding was present. It was firm in consistency, with well-defined borders, movable and tender (Figure 1). A Clinical diagnosis of tumour in the floor of mouth was suspected. Incisional biopsy was performed and sent for histopathological section. The report revealed sublingual salivary duct carcinoma.

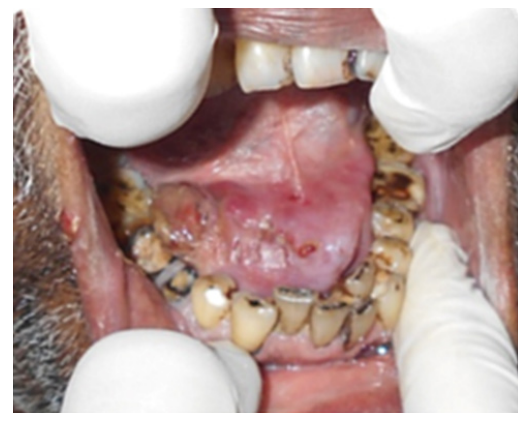

Figure I Intraoral figure showing a well-defined swelling on the floor of the mouth.

\section{Histopathology}

Laboratory investigations revealed a normal hemogram. Microscopic picture showed cribriform pattern with solid nests of round to oval tumour cells having comedo necrosis in the centre with dense fibrous stroma. Infiltrating component of diffuse invasive growth into adjacent bone and soft tissues was present. Scattered tumour cells in the fibrous stroma were also observed, a diagnosis of salivary duct carcinoma was confirmed (Figure 2,3).

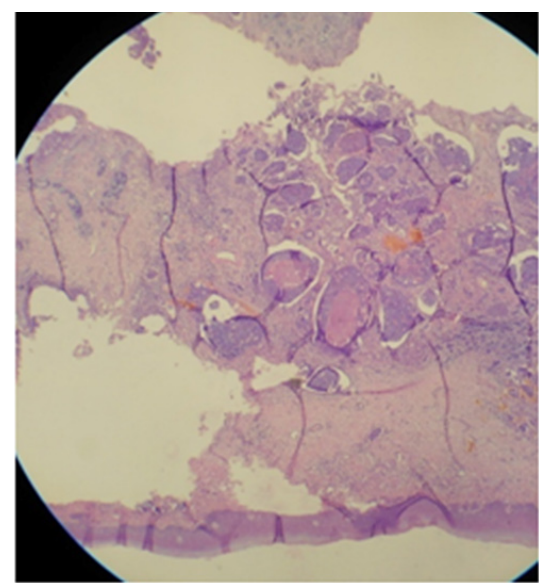

Figure 2 Histopathological picture $4 x$ - It shows salivary duct carcinoma with a cribriform pattern and central necrosis.

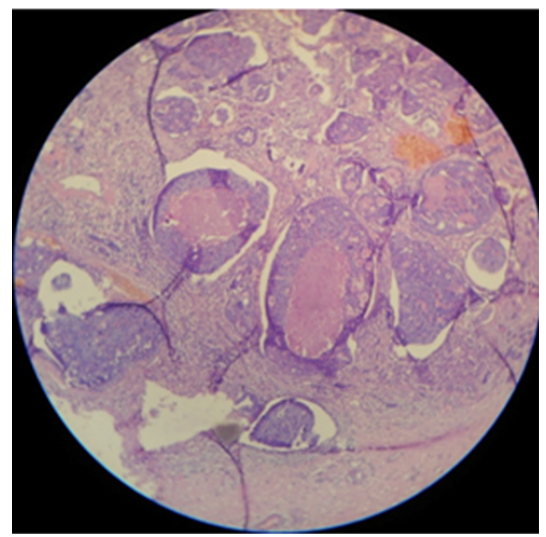

Figure 3 Histopathological picture - 40x magnification of histopathological specimen. 


\section{Discussion}

Salivary duct carcinoma of the parotid gland is an uncommon tumor, highly aggressive. About 200 cases have been reported in the English literature. Most of the duct carcinomas of the parotid gland have been reported in men in the age group of 38-76 years. It frequently involves the extracranial portion of the facial nerve and has a propensity to metastasize through the temporal bone via perineural spread. ${ }^{4}$ Gingival metastasis have also been reported. ${ }^{5}$ Rarely, submandibular glands and minor salivary glands are concerned. Salivary duct carcinoma may develop in some cases on the basis of pre-existing pleomorphic adenoma, but it can also occur de novo. In the present case patient was 61 years. The tumour was present in the floor of the mouth, and thereby the tumour originated from the ducts of the sublingual salivary glands. However, many authors have reported salivary duct carcinomas with morphological criteria of comedo pattern in parotid gland ducts. ${ }^{6}$ The present case has comedo pattern morphology arising from the duct of sublingual salivary gland. The tumour cells were arranged in solid tumour nests and frequently had comedo necrosis with fibrosis/sclerotic stroma. The infiltrating desmoplastic component had similarities to ductal breast carcinoma. ${ }^{\text {? }}$ The parotid duct and gland were uninvolved. No primary lesion in the breast was present not to misinterpret as metastatic deposits because of morphological resemblance to the tumour. Differential diagnosis comprises adenoid cystic carcinoma, metastasis of other adenocarcinomas, such as the carcinoma of the thyroid gland and the comedocarcinoma of the breast. Because of its poor prognosis, rapid intervention with radical therapy is recommended.

\section{Treatment}

In patients with involvement of the submandibular or minor salivary glands, tumor resection with wide margins of surrounding tissue is indicated to control local disease. ${ }^{8}$ The effects of adjuvant postoperative radiotherapy cannot be evaluated with certainty but many authors suppose that the aggressiveness of this tumor justifies adjuvant measures. Postoperative radiation therapy is indicated in case of extraparotid extension, pathological resection margins, cervical lymph node metastasis, lymphatic embolus, and/or neurologic invasion. Chemotherapy is generally reserved for metastatic forms of the disease.

\section{Acknowledgments}

None.

\section{Conflicts of interest}

The authors declare that there is no conflict of interest.

\section{References}

1. Seifert G, Caselitz J. Epithelial salivary gland tumors: Tumor markers. In: Fenoglio-Preiser CM, Wolff M, Rilke F, editors. Progress in surgical pathology, Springer Berlin Heidelberg, New York, USA;1989;157-187.

2. Gal R, Strauss M, Zohar Y, et al. Salivary duct carcinoma of the parotid gland. Cytologic and histopathologic study. Acta Cytol. 1985;29(3):454 456.

3. Kleinsasser O, Klein HJ, Hubner G. Salivary duct carcinoma. A group of salivary gland tumors analogous to mammary duct carcinoma. Arch Klin Exp Ohren Nasen Kehlkopfheilkd. 1968;192(1):100-105.

4. Nguyen BD, Roarke MC. Salivary duct carcinoma with perineural spread to facial canal: F-18 FDG PET/CT detection. Clin Nucl Med. 2008;33(12):925-928.

5. Bernabé DG, Veronese LA, Miyahara GI, et al. Gingival metastasis from salivary duct carcinoma of the parotid gland. $J$ Periodontol. 2008;79(4): 748-752.

6. Eriksen HE, Greisen O, Hastrup N. Duct carcinoma of the parotid gland. Journal of Laryngology and Otology. 1987;101(6):636- 638

7. Hellquist HB, Karlsson MG, Nilsson C. Salivary duct carcinoma: A highly aggressive salivary gland tumour with over expression of C-erbB-2. $J$ Pathol. 1994;172(1):35-44.

8. Jaehne M, Roeser K, Jaekel T, et al. Clinical and immunohistologic typing of salivary duct carcinoma: A report of 50 cases. Cancer. 2005;103(12):2526-2533. 